\title{
Article \\ Calculating the Inrush Current of Superconducting Transformers
}

\author{
Grzegorz Komarzyniec
}

check for

updates

Citation: Komarzyniec, G

Calculating the Inrush Current of Superconducting Transformers. Energies 2021, 14, 6714. https:// doi.org/10.3390/en14206714

Academic Editor: Pawel Rozga

Received: 3 September 2021

Accepted: 13 October 2021

Published: 15 October 2021

Publisher's Note: MDPI stays neutral with regard to jurisdictional claims in published maps and institutional affiliations.

Copyright: (C) 2021 by the author. Licensee MDPI, Basel, Switzerland. This article is an open access article distributed under the terms and conditions of the Creative Commons Attribution (CC BY) license (https:// creativecommons.org/licenses/by/ $4.0 /)$.
Faculty of Engineering and Computer Science, Lublin University of Technology, Nadbystrzycka 38A, 20-618 Lublin, Poland; g.komarzyniec@pollub.pl

\begin{abstract}
Under certain circumstances, after connecting a superconducting transformer to the power network, a high value current may flow through its windings. This current can exceed the critical value of the superconductor many times and cause the windings to lose their superconductive state. Loss of superconductive state of the windings may result in thermal interruption of their continuity as a result of conduction of a current of very high density. The mathematical relationships used to calculate the inrush current of conventional transformers do not work well for the calculation of superconducting transformers. This is due to the properties of superconducting materials used in the windings, first of all to the stepwise changes of the windings' resistance when exiting the superconducting state and when returning to this state. The article presents the mathematical dependencies allowing to calculate the pulse waveforms of the inrush current of these transformers are derived. Basic electrical circuit sizes are used in the calculations, making the calculations quick and easy. Using the formulas, calculations of the inrush current of $8.5 \mathrm{kVA}$ and $13.5 \mathrm{kVA}$ superconducting transformers. The results were verified with the results of the inrush current measurements, achieving good compliance.
\end{abstract}

Keywords: inrush current; superconductivity; transformer

\section{Introduction}

A high value current may flow through the transformer windings not only at short circuit or overload, but under certain circumstances even after the transformer has been connected to the mains. The current at the switching on of an unloaded transformer can reach a value of up to 20 times higher than the rated current [1,2]. The time of the inrush current fade can, in the case of large power transformers, reach several thousand periods of supply voltage.

Conventional transformers, i.e., with copper or aluminum windings, are elements of the power system with a relatively low failure rate. The maintenance of superconducting transformers (HTS transformer) in a faultless state is hampered by the tendency of their windings to easily emerge from the superconductive state. The inrush current of a high value and long decay time may not only make it difficult to connect the superconducting transformer to the mains, but also leads to thermal damage of its windings. Therefore, it is important to counteract the effects of this current $[1,3,4]$. This requires learning about the mechanism for the development of the inrush current in superconducting transformers, which are different from those in conventional transformers, as well as for the capturing of this phenomenon by mathematical relationships. This will allow the methods of limiting the inrush current of conventional transformers, which are still being developed [5-8], to be transferred to superconducting transformers.

The inrush current of conventional transformers is a relatively well-recognised phenomenon, both through theoretical analysis and experimental research on real transformers [9-12]. Specht and Holcomb [13-15] in 1951 and 1961 gave relationships for the inrush current of conventional transformers that are still used in calculations today [16]. Formulas to approximate the shape of the inrush current are proposed in $[17,18]$. Transformer 
models during inrush current are presented in [19-25]. Some of these models are based on electromagnetic-circuit analysis [21,25]. These models need to have transformer detail data which may be difficult to obtain. The B-H curve of the transformer core plays an important role in the turn-on current analysis. Analytical equations using the B-H curve to model the turn-on current are given in papers $[17,18,20,22]$. The magnitude of the first cycle inrush current is important for transformer design and protection. Therefore, analytical formulas to estimate the peak of the inrush current during the first cycle as a function of switching angle are presented in [26-29]. Due to the importance of the inrush current envelope for transformer and system protection, analytical formulas to estimate the inrush current envelope are presented in $[13,14,30]$. These formulas require some detailed data like detailed core dimensions, in addition to the electrical parameters and magnetic core characteristics.

The literature on the inrush current of superconducting transformers is relatively scarce and concentrates mainly on its waveforms obtained experimentally for existing transformers [31-33]. Meanwhile, calculation methods used in calculating the inrush current of conventional transformers do not work well in calculating this current for superconducting transformers, mainly because of the different parameters and characteristics of the superconducting wires with respect to conventional winding wires. This paper proposes a solution to this problem.

The mathematical descriptions proposed in the presented literature does not take into account dynamic changes of the windings' resistance, which leads to incorrect calculations for superconducting transformers. This article proposes a solution to this problem and derives mathematical relationships describing the course of the inrush current of superconducting transformers. Due to the limited amount of data concerning the inrush current phenomenon of superconducting transformers, the given dependencies were verified on the designed and built by the author of the paper transformers of this type.

\section{Superconducting Transformer}

Superconducting transformers differ from conventional ones mainly in the material from which their superconducting windings are made [34-36]. The use of superconducting winding materials determines the remaining differences in the construction of both types of transformers [37-39].

The diagram of an HTS transformer in the idle state (Figure 1) does not differ significantly from that of a conventional transformer, with the difference that resistance $R$ representing power losses in the high-temperature superconducting primary winding (HTS winding) of the HTS transformer is nonlinear as a function of changes in current $I$, magnetic field strength $H$ and temperature $T$. The nonlinearity of this resistance has a significant impact on the inrush current of the transformer. In the superconductive state of the winding, resistance $R$ is equal to zero. This resistance increases rapidly, in approximately $10^{-12} \mathrm{~s}$, when the critical parameters of the superconductor are exceeded, when the winding goes to the resistive state.

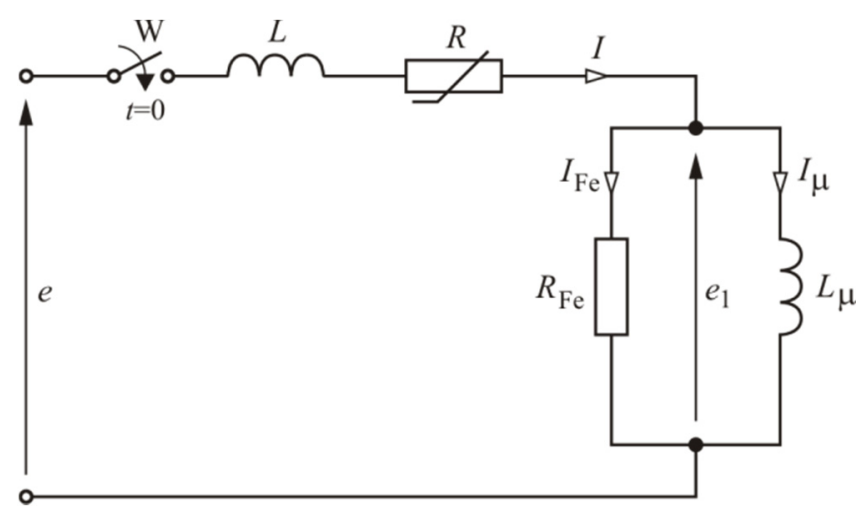

Figure 1. Scheme of a single-phase HTS transformer in the idle state. 
Critical current $I_{\mathcal{C}}$, critical temperature $T_{c}$ and critical magnetic field strength $H_{c}$ determine the critical area of the superconducting winding (Figure 2) [40,41]. The real critical parameters $T_{c r}, H_{c r}, I_{c r}$ of the superconducting winding have lower values and determine the location of the superconductor's working point $\left(P_{c r}\right)$ on the critical surface. Maintaining the superconductivity of the winding is only possible when the temperature, magnetic field strength and current strength are simultaneously lower than the real critical values, i.e., when the superconductor's working point $\left(P_{w}\right)$ is located under a critical surface and is determined by $T_{w}, H_{w}, I_{w}$.

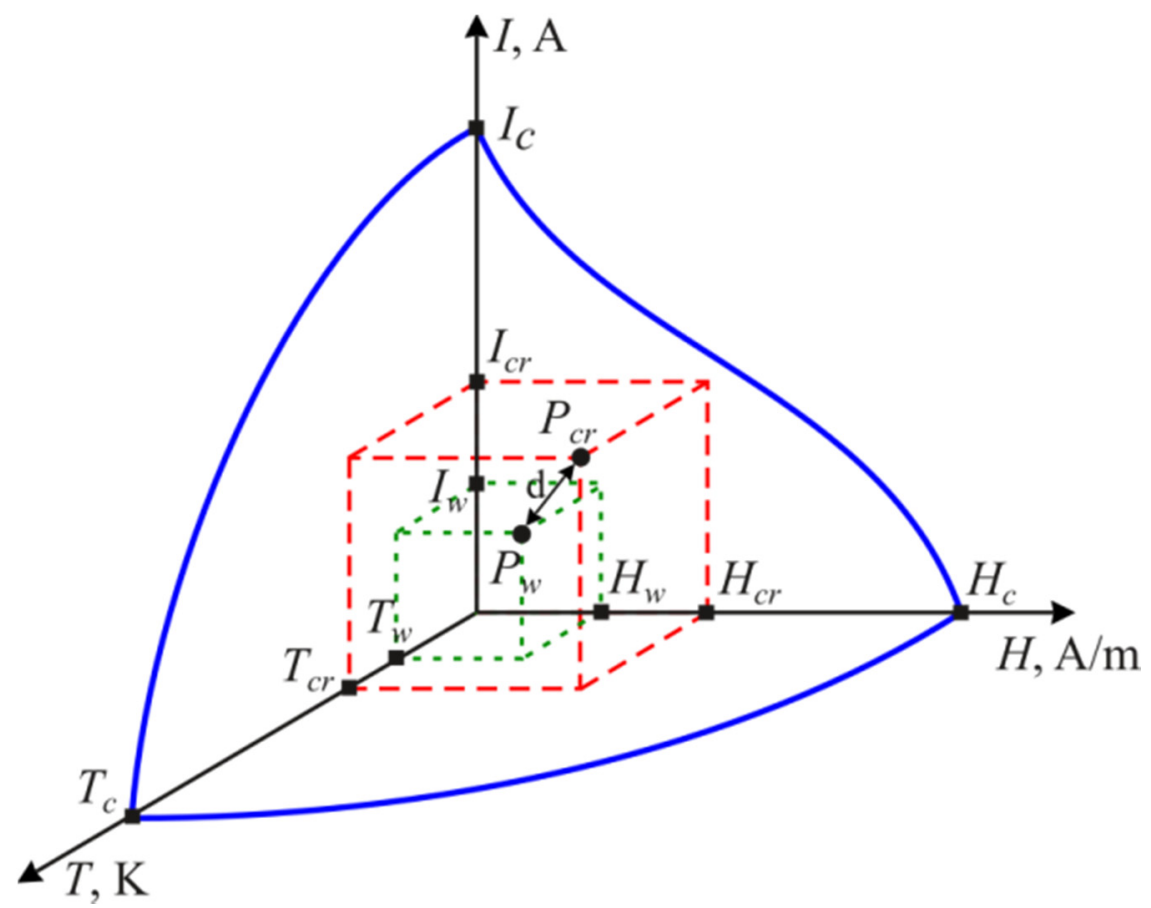

Figure 2. Critical surface of a superconductor.

Due to the high critical values of the magnetic field strength of modern superconducting materials, its influence on the course of the inrush current was omitted from the considerations. The impact of temperature changes is considered indirectly by assuming lower critical current values of the superconductor with its temperature increase. This approach allowed to simplify the transition characteristics of the HTS transformer's winding to the function of two variables $R=f(I)$, as shown in Figure 3 .

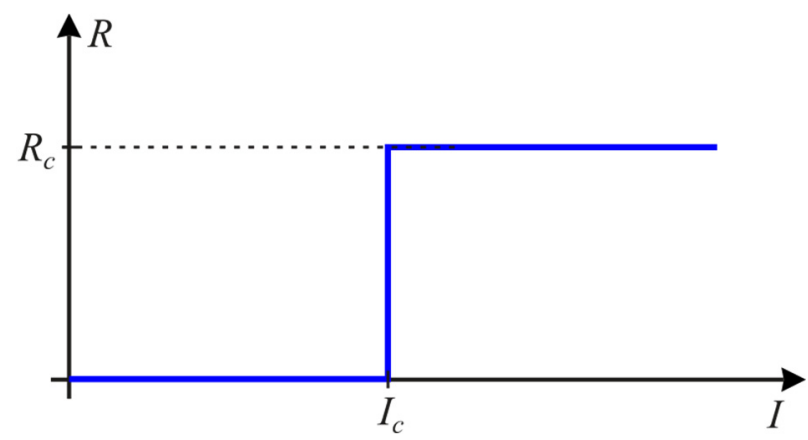

Figure 3. Simplified transition characteristics of a superconductor.

\section{Stream in the Transformer Core after Switching on}

Knowing the time course of the flux, after switching on the transformer, it is possible to determine the time course of the inrush current from the magnetisation characteristic $\Phi=f(I)[42,43]$. 
Initially, the connection of an unloaded single-phase transformer (Figure 1) to a sinusoidal source (Figure 4) will be considered. The constant resistance $R$ is assumed for the entire duration of the inrush current. The impedance of the power grid and the impedance of the power source are ignored.

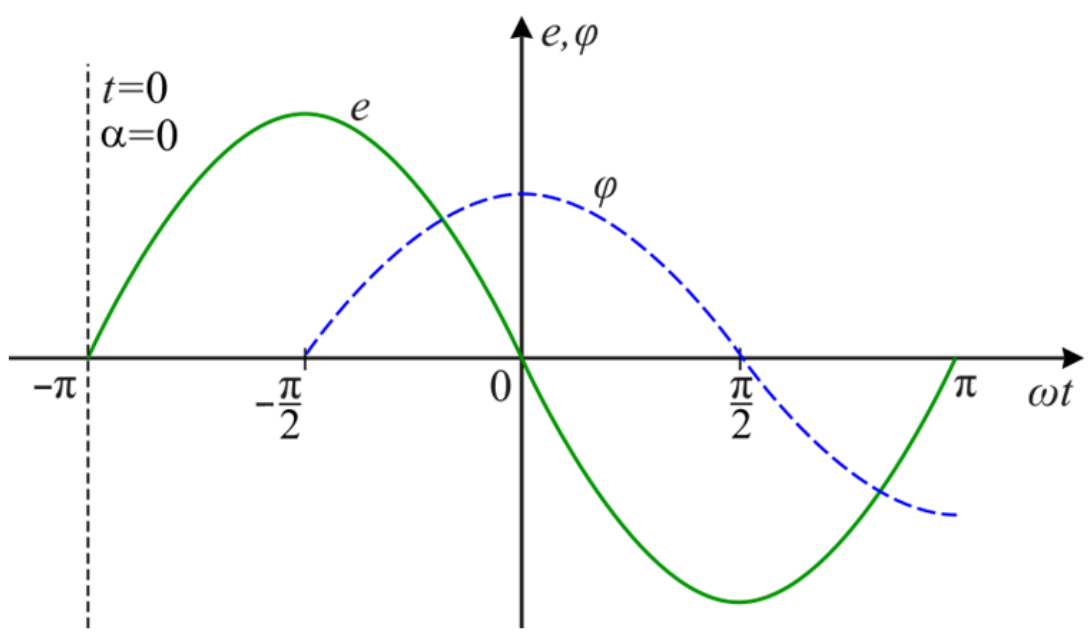

Figure 4. Course of the voltage supplying the transformer.

The course of the inrush current is influenced by the shape of the magnetisation curve in the saturation area of the transformer core [44,45]. Figure 5 shows a simplified shape of the magnetisation curve adopted for the calculation $[15,46,47]$.

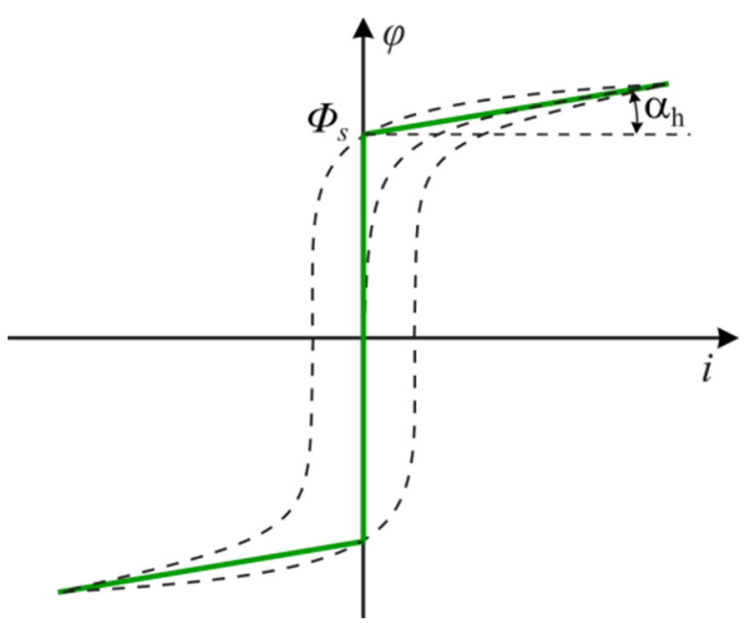

Figure 5. Simplified shape of the magnetisation curve.

The circuitry in Figure 1 is described by the equations [18]:

$$
\begin{gathered}
e=R i+L \frac{d i}{d t}+e_{1} \\
e_{1}=L_{\mu} \frac{d i_{\mu}}{d t}=R_{F e} i_{F e}
\end{gathered}
$$

Assuming that the transformer is switched on at the angle $-\pi$ (Figure 4 ) the basic equation of the transformer operation can be written as:

$$
-\sqrt{2} E \sin (\omega t+\alpha)=N \Phi \frac{R}{L}+z \frac{d \Phi}{d t}
$$


After the integration of Equation (3), the expression for flux is obtained:

$$
\varphi=-\Phi_{m} \sin (\omega t+\alpha-\delta)+\mathrm{A} e^{-\frac{R}{X} \omega t}
$$

where $\mathrm{A}$ is the integration constant determined from the initial conditions.

After the transformer has been connected to the power network, the value of the excitation current at the first moment must be equal to zero. However, there is a residual magnetism flux $\Phi_{r}\left(\varphi=\Phi_{r}\right.$ dla $\left.\omega t=-\pi\right)$ and therefore the constant $\mathrm{A}$ is:

$$
\mathrm{A}=-\Phi_{m} \sin (\pi-\alpha+\delta) e^{-\frac{R}{X} \pi}+\Phi_{r} e^{-\frac{R}{X} \pi}
$$

Ultimately, the flux equation has a form:

$$
\begin{aligned}
& \Phi=-\Phi_{m} \sin (\omega t+\alpha-\delta)-\Phi_{m} \sin (\pi-\alpha+\delta) \mathrm{e}^{-\frac{R}{X}(\pi+\omega t)} \\
& +\Phi_{r} \mathrm{e}^{-\frac{R}{X}(\pi+\omega t)}
\end{aligned}
$$

where the angle of the phase shift $\delta$ is:

$$
\delta=\operatorname{tg}^{-1} \frac{X}{R}
$$

Equation (6) contains two components-fixed:

$$
\varphi_{f}=-\Phi_{m} \sin (\omega t+\alpha-\delta)
$$

and disturbing:

$$
\varphi_{d}=-\Phi_{m} \sin (\pi-\alpha+\delta) \mathrm{e}^{\frac{R}{X}(\pi+\omega t)}+\Phi_{r} \mathrm{e}^{-\frac{R}{X}(\pi+\omega t)}
$$

From relation (6) it follows that the magnetic flux $\varphi$ reaches its highest peak moment after switching on the transformer. This value depends on the phase of the supply voltage e and the value of the residual magnetism flux $\Phi_{r}$ at the moment of switching on the transformer and the value of the ratio $R / X$ of the electrical circuit [48].

Let us assume that we are omitting the resistance of the primary winding and the active component to cover iron losses $\left(R=0 \mathrm{i} R_{\mathrm{Fe}}=\infty\right)$ and the flux in the transformer core is delayed to the voltage by an angle $\pi / 2$ (Figure 4 ). The inrush current will not appear when the transformer is switched on when the voltage e reaches its maximum value and there is no residual magnetism flux in the transformer core $\left(\Phi_{r=0}\right)$.

The least favourable conditions for switching on the transformer occur when the supply voltage e passes through zero. Because at the moment of switching on the transformer the flux in the core must be equal to zero (if the residual magnetism flux is omitted, i.e., $\Phi_{\mathrm{r}}=0$ ), a one-way flux component must occur. This component, when added to the course of a fixed flux, causes the peak value of the flux to double:

$$
\Phi_{M}=2 \Phi_{m}
$$

As can be seen from relation (6), the residual magnetism flux $\Phi_{r}$ has a significant influence on the course of the flux $\varphi$. Expression (6) reaches its highest value:

$$
\Phi_{M}=2 \Phi_{m}+\Phi_{\mathrm{r}}
$$

Such a high flux value leads to saturation of the transformer core, at which the peak value of the inrush current reaches significant values.

From Equation (6) it appears that the reaction $X$ is a measure of circuit inertia. Resistance $R$ is responsible for damping the unidirectional component of the disturbing flux, 
and thus reducing the peak value of the inrush current and shortening its duration [16]. The value of the flux is reduced by the value expressed in the equation:

$$
\Delta \Phi=\frac{1}{z} \int_{-\pi / \omega}^{t} \operatorname{Rid} t
$$

If the resistance is omitted in the circuit from Figure $1(R=0)$, then the attenuation of the one-way flux component does not occur and the flux has an undamped course described by the relation:

$$
\varphi=\Phi_{m}+\Phi_{m} \cos \omega t+\Phi_{r}
$$

Therefore, the inrush current is also undamped.

\section{Inrush Current of Superconducting Transformer}

The inrush current, similar to the magnetic flux described by Equation (6), has two components: fixed and transient. The fixed component is the periodically alternating current drawn by the transformer to excite the flux in the core and cover the power losses in the transformer in its steady state. This current is between 1 and $10 \%$ of the rated current, so it will be omitted from consideration. The disruptive component of the inrush current is a unidirectional current impulse that appears when the transformer core is saturated and this component will be taken into account.

The resistance $R$ of the equivalent circuit diagram of the HTS transformer (Figure 1) depends on the state of the primary superconductor winding. We assume that the transition characteristics of the superconducting windings are as shown in Figure 3. For the calculations it has been assumed that the resistance $R$ in the superconductive state has a value greater than zero. Such an approach allows for taking into account the residual resistance of the superconductor, connection resistances, current bushings resistances and the power network resistance. It is assumed that when the transformer is switched on, its windings are in a superconductive state. It is assumed that the temperature of the windings does not exceed the critical temperature and the effect of the magnetic field strength is ignored for the duration of the inrush current.

In the saturation state of the core, the scheme of an HTS transformer in the idle state (Figure 1 ) is simplified to a serial connection of the resistance of the primary winding $R$ and the inductance of that winding $L$, as shown in Figure $6[14,15]$.

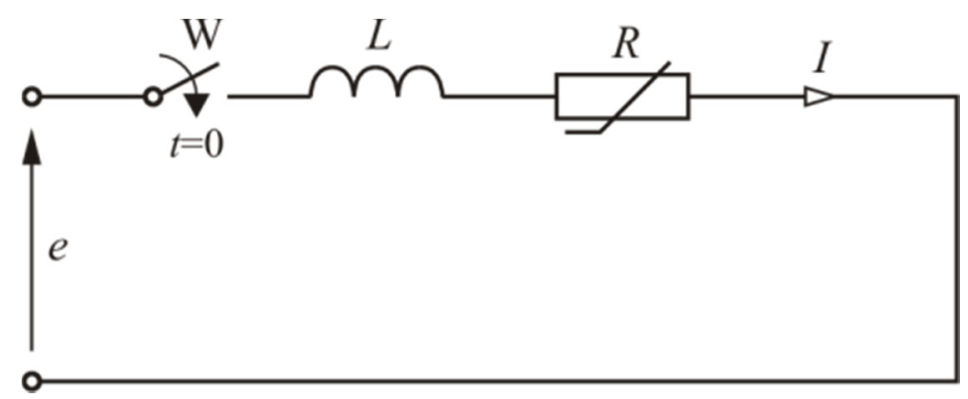

Figure 6. Replacement diagram of HTS transformer at core saturation.

When the $\mathrm{W}$ switch is closed at $t=0$, the circuit from Figure 6 is described by the equation:

$$
e=-\sqrt{2} E \sin \omega t=R i+L \frac{d i}{d t}
$$

The unidirectional current appears when the momentary value of the flux $\Phi$ exceeds the value of the saturation flux of the core $\Phi_{n}$, which takes place for $\omega t=-\theta$ (Figure 7). 
By converting Equation (13), including $\omega t=-\theta$ and $\varphi=\Phi_{n}$, a formula is obtained for the angle at which the unidirectional current pulse appears:

$$
\theta=\cos ^{-1} \frac{\Phi_{s}-\Phi_{m}-\Phi_{r}}{\Phi_{m}}
$$

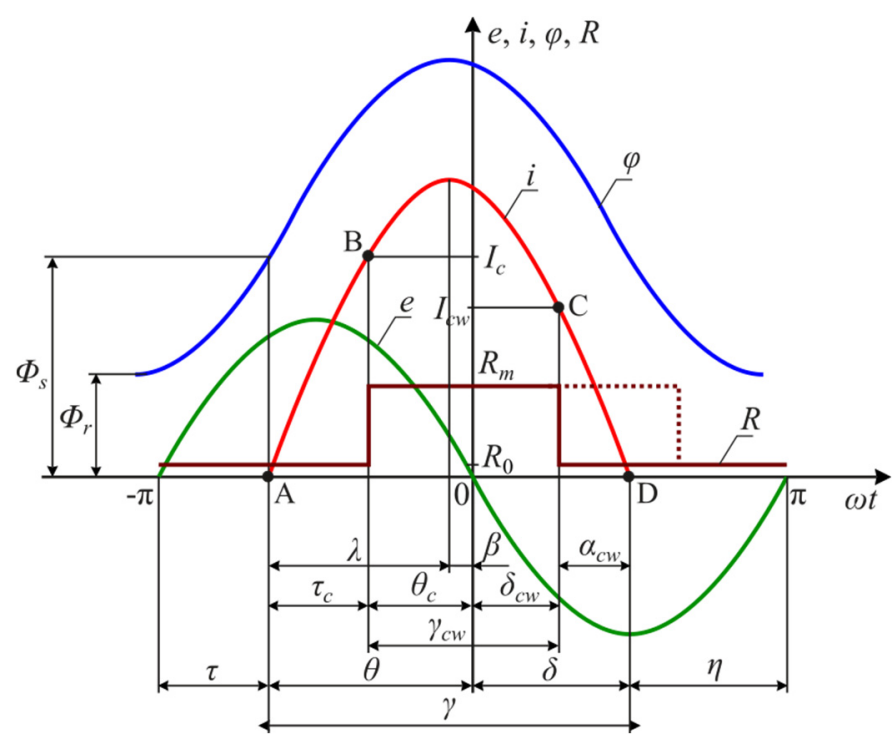

Figure 7. Voltage, flux, current and resistance of a superconducting winding.

In Figure 7, the transformer is switched on when the voltage $e$ passes through the zero value, i.e., for angle $-\pi$. The primary winding of the HTS transformer is in the superconductive state and its resistance is close to zero $\left(R=R_{0}\right)$. The flux reaches the saturation value of the transformer core $\Phi_{s}$ for the angle $-\theta$. At this point, a unidirectional current pulse $i$ appears. The increasing current pulse reaches the value of critical current of the primary winding $i=I_{c}$ for the angle $-\theta_{c}$. At this point, the primary winding of the transformer passes to the resistive state and its resistance increases to $R=R_{m}$. The falling unidirectional current pulse reaches the critical current at which the primary winding of the transformer returns to the superconductive state $i=I_{c w}$ for angle $\delta_{c w}$. For the $\delta$ angle, the transformer core comes out of saturation and the unidirectional current $i$ disappears. As a result of the two changes in the state of the circuit from Figure 6, the unidirectional current pulse $i$ is described by three different equations: (1) for the value of $i$ from $-\theta$ to $-\theta_{c}$, (2) for the value of $i_{c}$ from $-\theta_{c}$ to $\delta_{c w}$ and (3) for the value of $i_{c w}$ from $\delta_{c w}$ to $\delta$.

Under initial conditions, for $\omega t=-\theta$, the unidirectional current must have a value equal to zero. By substituting $i=0$ and $\omega t=-\theta$ for Equation (14), the formula for the unidirectional component of the inrush current is obtained:

$$
i=-\frac{\sqrt{2} E X}{Z^{2}}\left(\begin{array}{l}
\frac{R}{X} \sin \omega t-\cos \omega t+ \\
\left(\frac{R}{X} \sin \theta+\cos \theta\right) e^{-\frac{R}{X}(\omega t+\theta)}
\end{array}\right)
$$

where:

$$
X=\omega L
$$

and

$$
Z=\sqrt{R^{2}+X^{2}}
$$

If the HTS transformer winding does not come out of the superconduction state, the unidirectional current pulse over its entire duration can be described by Equation (16). 
By converting Equation (16) under boundary conditions $\omega t=\delta$ and $i=0$, the formula is obtained for the angle $\delta$ at which the unidirectional current disappears:

$$
\delta=\operatorname{tg}^{-1} \frac{e^{\frac{R}{X} \gamma}-\frac{R}{X} \sin \gamma-\cos \gamma}{\frac{R}{X} e^{\frac{R}{X} \gamma}+\sin \gamma-\frac{R}{X} \cos \gamma}
$$

Now let us assume that the primary winding of the HTS transformer comes out of the superconducting state for angle $-\theta_{c}$, as shown in Figure 7. At that point, Equation (16) is no longer correct. Assuming the boundary conditions $i=I_{c}$ and $\omega t=-\theta_{c}$ and introducing them into Equation (16), the formula for angle $\theta_{c}$ is obtained:

$$
\theta_{c}=\operatorname{tg}^{-1} I_{c} \frac{Z^{2}}{\sqrt{2} E X} \mathrm{~A}+\mathrm{B}
$$

where parameter $\mathrm{A}$ is a given dependence:

$$
\mathrm{A}=\frac{e^{\frac{R}{\mathrm{X}} \tau_{c}}}{\left(\sin \tau_{c}-\frac{R}{X} \cos \tau_{c}+\frac{R}{X} e^{\frac{R}{X} \tau_{c}}\right) \cos \left(\theta-\tau_{c}\right)}
$$

and $B$ is:

$$
\mathrm{B}=\frac{\frac{R}{X} \sin \tau_{c}+\cos \tau_{c}-e^{\frac{R}{X} \tau_{c}}}{\sin \tau_{c}-\frac{R}{X} \cos \tau_{c}+\frac{R}{X} e^{\frac{R}{X} \tau_{c}}}
$$

By solving the general Equation (14) of the circuit from Figure 6, for the initial conditions $i=I_{c}$ and $\omega t=-\theta_{c}$, the equation for the unidirectional current is obtained after the HTS transformer winding has passed to the resistive state:

$$
\begin{aligned}
& i_{c}=-\frac{\sqrt{2} E X}{Z^{2}}\left(\begin{array}{l}
\frac{R}{X} \sin \omega t-\cos \omega t+ \\
\left(\frac{R}{X} \sin \theta_{c}+\cos \theta_{c}\right) e^{-\frac{R}{X}\left(\omega t+\theta_{c}\right)}
\end{array}\right) \\
& +I_{c} e^{-\frac{R}{X}\left(\omega t+\theta_{c}\right)}
\end{aligned}
$$

Equation (23) is valid as long as the primary winding of the HTS transformer is in the resistive state and for the longest time until the current pulse disappears.

Let us now assume that the primary winding of the HTS transformer returns to the superconductive state for angle $\delta_{c w}$, as shown in Figure 7. The angle $\delta_{c w}$ is determined by substituting $i_{c}=I_{c w}$ and $\omega t=\delta_{c w}$ for Equation (23) and after transformations, the formula is obtained:

$$
\delta_{c w}=\operatorname{tg}^{-1}\left(I_{c}-I_{c w} e^{\frac{R}{X} \gamma_{c w}}\right) \frac{Z^{2}}{\sqrt{2} E X} \mathrm{G}+\mathrm{H}
$$

where parameter $\mathrm{G}$ is a given dependence:

$$
G=\frac{1}{\left(\frac{R}{X} e^{\frac{R}{X} \gamma_{c w}}-\frac{R}{X} \cos \gamma_{c w}+\sin \gamma_{c w}\right) \cos \left(\gamma_{c w}-\theta_{c}\right)}
$$

and $\mathrm{H}$ is:

$$
\mathrm{H}=\frac{e^{\frac{R}{X} \gamma_{c w}}-\frac{R}{X} \sin \gamma_{c w}-\cos \gamma_{c w}}{\frac{R}{X} e^{\frac{R}{X} \gamma_{c w}}-\frac{R}{X} \cos \gamma_{c w}+\sin \gamma_{c w}}
$$


By solving the general Equation (14) of the circuit from Figure 6, for the initial conditions $i=I_{c w}$ and $\omega t=\delta_{c w}$, the formula for the unidirectional current is obtained after recovering the state of superconductivity of the transformer winding:

$$
\begin{aligned}
& i_{c w}=-\frac{\sqrt{2} E X}{Z^{2}}\left(\begin{array}{l}
\frac{R}{X} \sin \omega t-\cos \omega t- \\
\left(\frac{R}{X} \sin \delta_{c w}-\cos \delta_{c w}\right) e^{-\frac{R}{X}\left(\omega t-\delta_{c w}\right)}
\end{array}\right) \\
& +I_{c w} e^{-\frac{R}{X}\left(\omega t-\delta_{c w}\right)}
\end{aligned}
$$

For the $\delta$ angle (Figure 7) the unidirectional current pulse fades. The angle $\delta$ is determined by substituting $i_{c w}=0$ and $\omega t=\delta$ for formula (27) and after transformations, the relation is obtained:

$$
\delta=\operatorname{tg}^{-1} I_{c w} \frac{Z^{2}}{\sqrt{2} E X} \mathrm{~K}+\mathrm{M}
$$

where parameter $\mathrm{K}$ is a given dependence:

$$
\mathrm{K}=\frac{1}{\left(\frac{R}{X} e^{\frac{R}{X} \alpha_{c w}}-\frac{R}{X} \cos \alpha_{c w}+\sin \alpha_{c w}\right) \cos \left(\alpha_{c w}+\delta_{c w}\right)}
$$

and $\mathrm{M}$ is:

$$
\mathrm{M}=\frac{e^{\frac{R}{X} \alpha_{c w}}-\frac{R}{X} \sin \alpha_{c w}-\cos \alpha_{c w}}{\frac{R}{X} e^{\frac{R}{X} \alpha_{c w}}-\frac{R}{X} \cos \alpha_{c w}+\sin \alpha_{c w}}
$$

A block diagram of the algorithm for calculating the turn-on current using the given formulas is shown in Figure 8. 


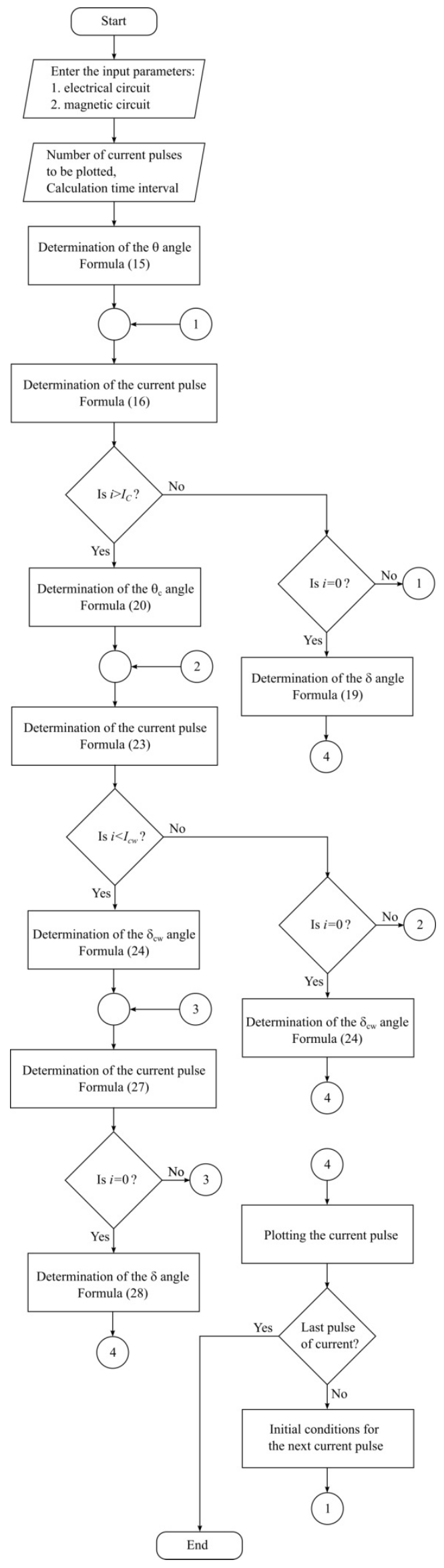

Figure 8. Block diagram of the calculation method. 


\section{Experimental Verification of Calculations}

The verification of the obtained formulas was carried out experimentally on two singlephase $8.5 \mathrm{kVA}$ and $13.8 \mathrm{kVA}$ superconducting transformers, the construction of which is shown in Figures 9 and 10. The rating data of the transformers are given in Table 1. For the core of the $8.5 \mathrm{kVA}$ transformer, a wound and cut core with a rectangular cross-section of $0.0049 \mathrm{~m}^{2}$, made of PN ET52-27 sheet metal with the trade symbol RZC-70/230/70, was used. The core of the $13.8 \mathrm{kVA}$ transformer was made as stepped and diagonally braided, with an area of $0.008 \mathrm{~m}^{2}$, from M150-30S electrotechnical sheet metal.

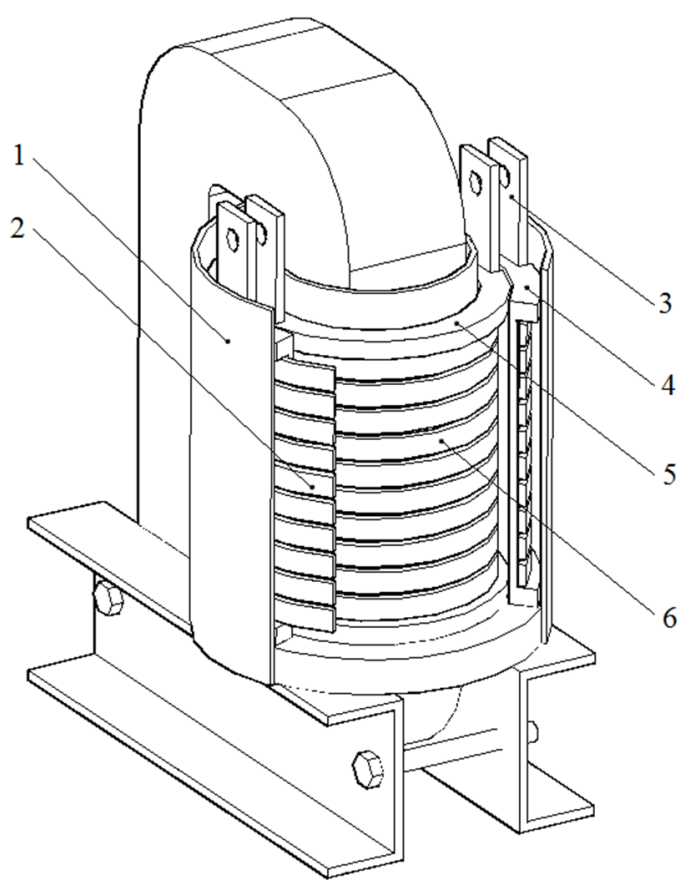

Figure 9. 8.5 kVA superconducting transformer construction, 1-cryostat, 2-primary winding HV, 3-connecting terminals, 4-primary winding carcass, 5-secondary winding carcass, 6-secondary winding LV.

Table 1. Parameters of 8.5 kVA and 13.8 kVA HTS Transformers.

\begin{tabular}{ccc}
\hline & $\mathbf{8 . 5} \mathbf{~ k V A}$ & $\mathbf{1 3 . 8 \mathbf { ~ k A }}$ \\
\hline Power & $8.5 \mathrm{kVA}$ & $13.8 \mathrm{kVA}$ \\
Frequency & $50 \mathrm{~Hz}$ & $50 \mathrm{~Hz}$ \\
Voltage $U_{n} \mathrm{HV} / \mathrm{LV}$ & $220 \mathrm{~V} / 110 \mathrm{~V}$ & $230 \mathrm{~V} / 60 \mathrm{~V}$ \\
Current $I_{n} \mathrm{HV} / \mathrm{LV}$ & $40 \mathrm{~A} / 80 \mathrm{~A}$ & $60 \mathrm{~A} / 230 \mathrm{~A}$ \\
Critical current $I_{c} \mathrm{HV} / \mathrm{LV}$ & $115 \mathrm{~A} / 115 \mathrm{~A}$ & $87 \mathrm{~A} / 333 \mathrm{~A}$ \\
Magnetic induction & $1.6 \mathrm{~T}$ & $1.6 \mathrm{~T}$ \\
Idle current & $3.1 \mathrm{~A}$ & $0.7 \mathrm{~A}$ \\
Short circuit voltage & $0.9 \%$ & $3.2 \%$ \\
\hline
\end{tabular}

The current bushings of the transformers were made of bar-shaped copper elements for the $8.5 \mathrm{kVA}$ transformer and cylindrical for the $13.8 \mathrm{kVA}$ transformer. The current bushings were connected to the superconducting windings through tin solder joints.

The superconducting windings were wound on glass composite carcasses and placed in cryostats made of the same material. The cooling liquid was nitrogen.

All electrical connections inside the cryostat were made with superconducting wires by tin soldering. 


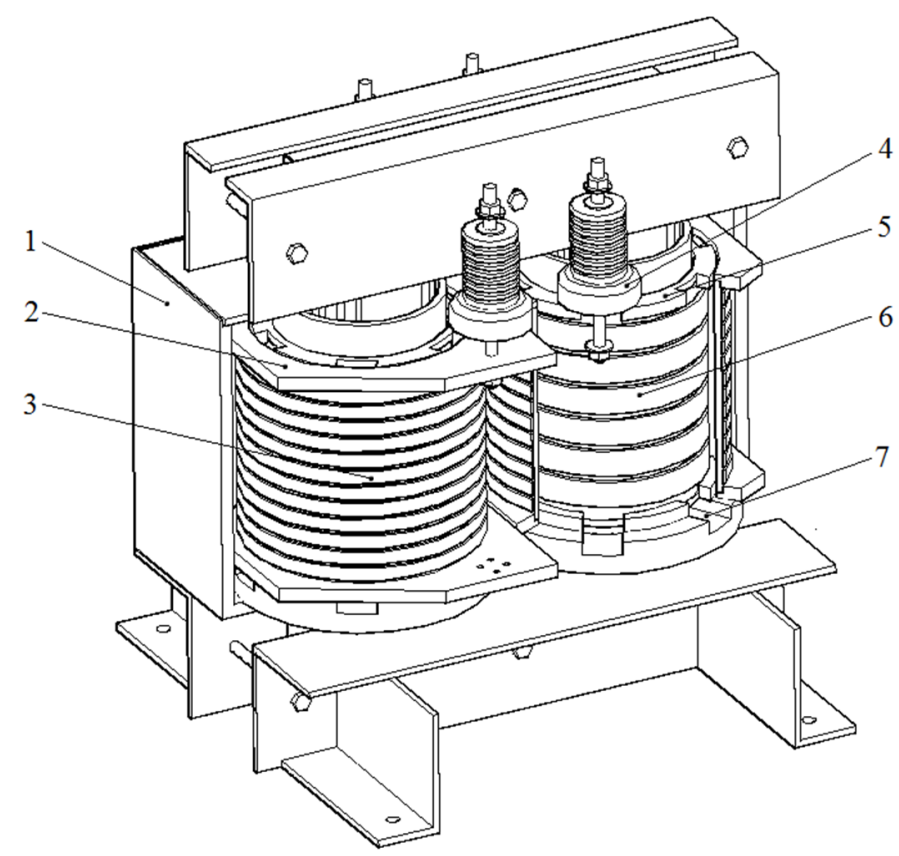

Figure 10. Construction of a $13.8 \mathrm{kVA}$ superconducting transformer, 1 -cryostat, 2-primary winding carcass, 3-primary winding HV, 4-current bushings, 5-secondary winding carcass, 6-secondary winding LV, 7-channels cooling.

The primary winding of the $8.5 \mathrm{kVA}$ transformer uses the SCS4050 superconducting tape (SuperPower Inc., Glenville, WV, USA) with a minimum critical current of $115 \mathrm{~A}$, at $77 \mathrm{~K}$ and in its own field. For the primary winding of the $13.8 \mathrm{kVA}$ transformer, the SCS4050-AP type tape with a minimum critical current of $87 \mathrm{~A}$. The secondary winding of the $8.5 \mathrm{kVA}$ transformer is made of SCS4050 tape and the $13.8 \mathrm{kVA}$ transformer is made of SCS12050-AP tape with a minimum critical current of $333 \mathrm{~A}$, at $77 \mathrm{~K}$ and in its own field. The parameters of the transformer windings used in the measurements are listed in Table 2. The SCS tapes have a layered structure consisting of a $1.6 \mu \mathrm{m}$ thick (RE)BCO type superconductor and several layers of resistive materials (Figure 11). The total thickness of the SCS4050 tape is $0.1 \mathrm{~mm}$ and the width is $4 \mathrm{~mm}$. The SCS12050-AP differs in width of $12 \mathrm{~mm}$. The winding resistances of the two transformers for different states of operation are given in Table 2.

Table 2. Winding parameters.

\begin{tabular}{|c|c|c|}
\hline & $8.5 \mathrm{kVA}$ & $13.8 \mathrm{kVA}$ \\
\hline Resistance of windings HV / LV (293 K) & $\begin{array}{l}6.36 \Omega / \\
3.1 \Omega\end{array}$ & $\begin{array}{l}2.9 \Omega / \\
0.57 \Omega\end{array}$ \\
\hline Resistance of windings HV / LV (77 K) & $\begin{array}{c}0.055 \mathrm{a} \Omega / \\
0.027 \mathrm{a} \Omega\end{array}$ & $\begin{array}{c}0.0466 \mathrm{a} \Omega / \\
0.0097 \mathrm{a} \Omega\end{array}$ \\
\hline $\begin{array}{l}\text { Resistance of the } \mathrm{HV} / \mathrm{LV} \text { winding after } \\
\text { transition to a resistive state }(77 \mathrm{~K})\end{array}$ & $\begin{array}{l}27 \mu \Omega / \\
13 \mu \Omega\end{array}$ & $\begin{array}{l}23 \mu \Omega / \\
5 \mu \Omega\end{array}$ \\
\hline Winding inductance HV / LV & $\begin{array}{l}1.7 \mathrm{mH} / \\
0.4 \mathrm{mH}\end{array}$ & $\begin{array}{c}290 \mu \mathrm{H} / \\
18 \mu \mathrm{H}\end{array}$ \\
\hline Winding cross-sectional area HV & $0.0138 \mathrm{~m}^{2}$ & $0.0244 \mathrm{~m}^{2}$ \\
\hline Length of the winding wires $\mathrm{HV} / \mathrm{LV}$ & $\begin{array}{l}55 \mathrm{~m} / \\
27 \mathrm{~m}\end{array}$ & $\begin{array}{l}68 \mathrm{~m} / \\
28 \mathrm{~m}\end{array}$ \\
\hline
\end{tabular}




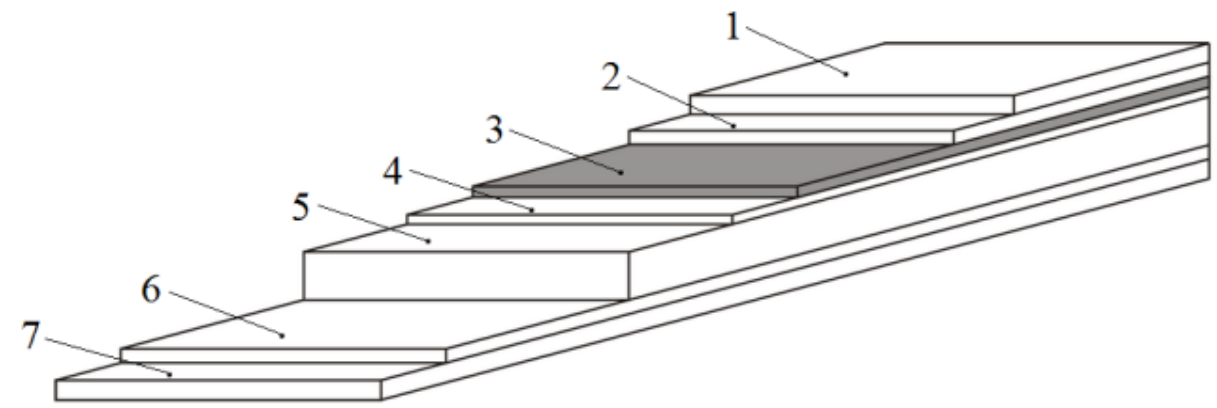

Figure 11. Structure of SCS tape made by SuperPower Inc.: 1-copper, 2-silver, 3-(Re)BCO, 4-Buffer zone, 5-Hastelloy, 6-silver, 7-copper.

The transformers are described in more detail in the articles [49,50]. The data needed for the calculations were obtained from the inrush current measurements described in the article [51]. The measurement system in which the inrush current was measured is shown in Figures 12 and 13 shows the electrical circuit diagram. The current waveform was recorded indirectly by measuring the voltage drop across the shunt. The power circuit parameters are given in Table 3. The resistance of the shunt was $1 \mathrm{~m} \Omega$ a class of accuracy 0.5 . The electrical connections were made with copper wires with a conductor diameter of $6 \mathrm{~mm}$ and a total length of $3 \mathrm{~m}$. The resistance of the power cables was $11 \mathrm{~m} \Omega$, while the inductance is negligibly small. The power source was a $230 \mathrm{~V} / 0 \div 230 \mathrm{~V}$ autotransformer with a power output of $23.4 \mathrm{kVA}$. The resistance of the power source was $1.5 \Omega$ and its impedance was $128 \mathrm{mH}$. Power on the HTS transformer was performed when the automatic switching system detected the grid voltage passing through zero. The switching circuit was an electronic circuit of our own design. Simultaneously, the data acquisition system using the NI DAQ PCI-6280 card and a PC with an application written in the LabVIEW environment was started.

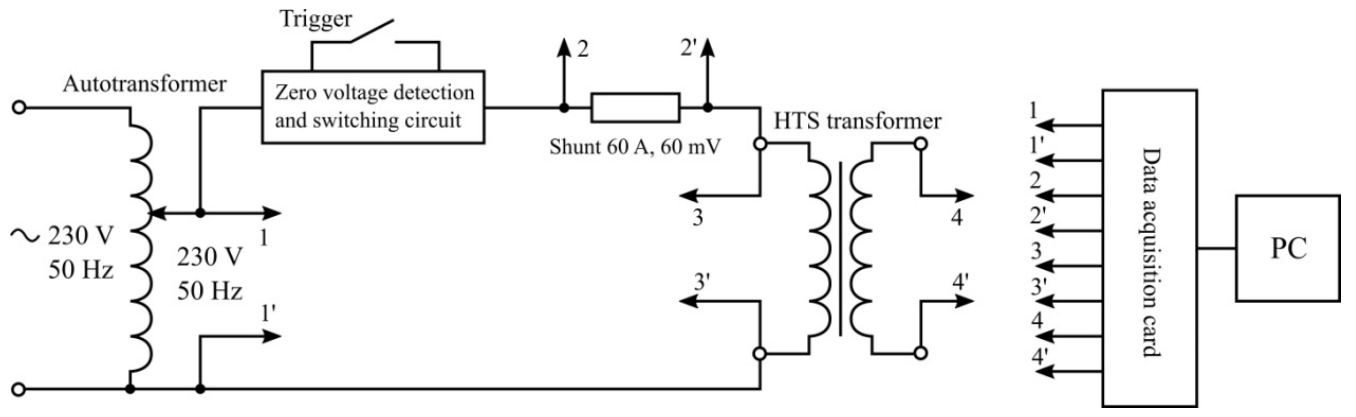

Figure 12. Measuring system.

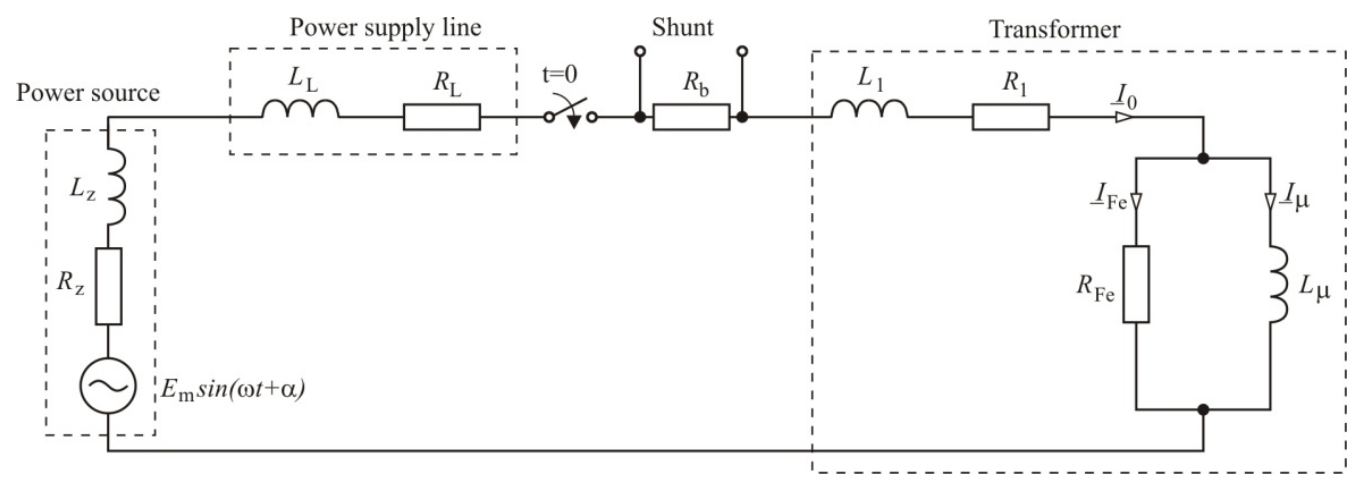

Figure 13. Electrical circuit diagram. 
Table 3. Electrical circuit parameters.

\begin{tabular}{|c|c|c|c|c|c|c|c|c|c|c|}
\hline \multicolumn{4}{|c|}{ Power Source } & \multicolumn{2}{|c|}{ Supply Line } & \multirow{3}{*}{$\begin{array}{c}\text { Shunt } \\
\boldsymbol{R}_{b}\end{array}$} & \multicolumn{4}{|c|}{ Transformer } \\
\hline \multirow{2}{*}{$L_{Z}$} & \multirow{2}{*}{$R_{Z}$} & \multirow{2}{*}{$E_{Z}$} & \multirow{2}{*}{$f_{Z}$} & \multirow{2}{*}{$L_{L}$} & \multirow{2}{*}{$R_{L}$} & & \multicolumn{2}{|c|}{$8.5 \mathrm{kVA}$} & \multicolumn{2}{|c|}{$13.8 \mathrm{kVA}$} \\
\hline & & & & & & & $R_{F e}$ & $X_{\mu}$ & $R_{F e}$ & $X_{\mu}$ \\
\hline $128 \mathrm{mH}$ & $1.5 \Omega$ & $230 \mathrm{~V}$ & $50 \mathrm{~Hz}$ & 0 & $11 \mathrm{~m} \Omega$ & $1 \mathrm{~m} \Omega$ & $960 \Omega$ & $71 \Omega$ & $1104 \Omega$ & $224 \Omega$ \\
\hline
\end{tabular}

Comparisons of the first inrush current pulses shown in Figures 14 and 15 show the discrepancies in the waveforms of the measured and calculated pulses.

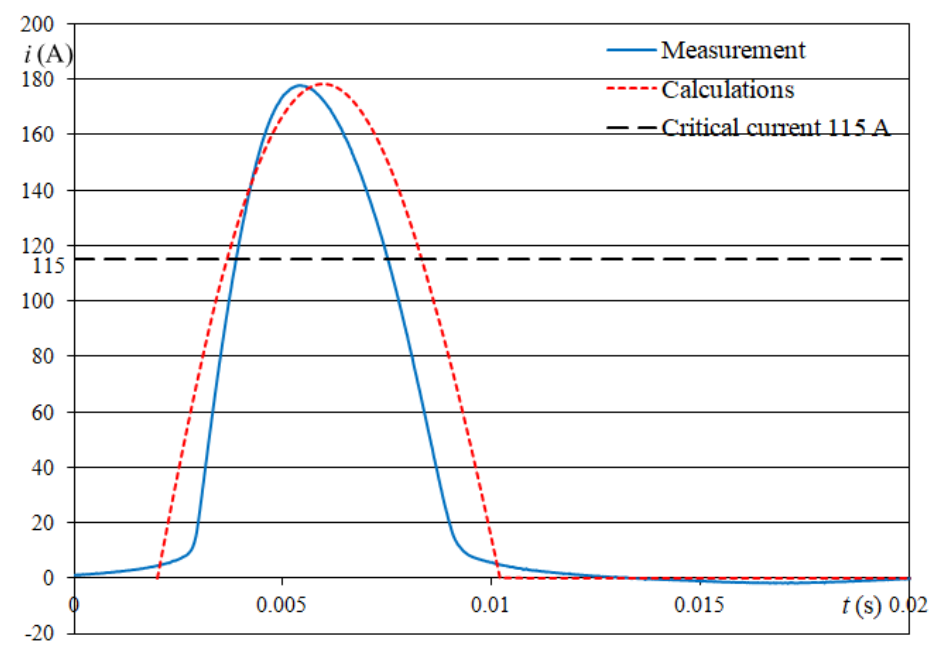

Figure 14. First impulse of the inrush current of the $8.5 \mathrm{kVA}$ HTS transformer, measured and calculated.

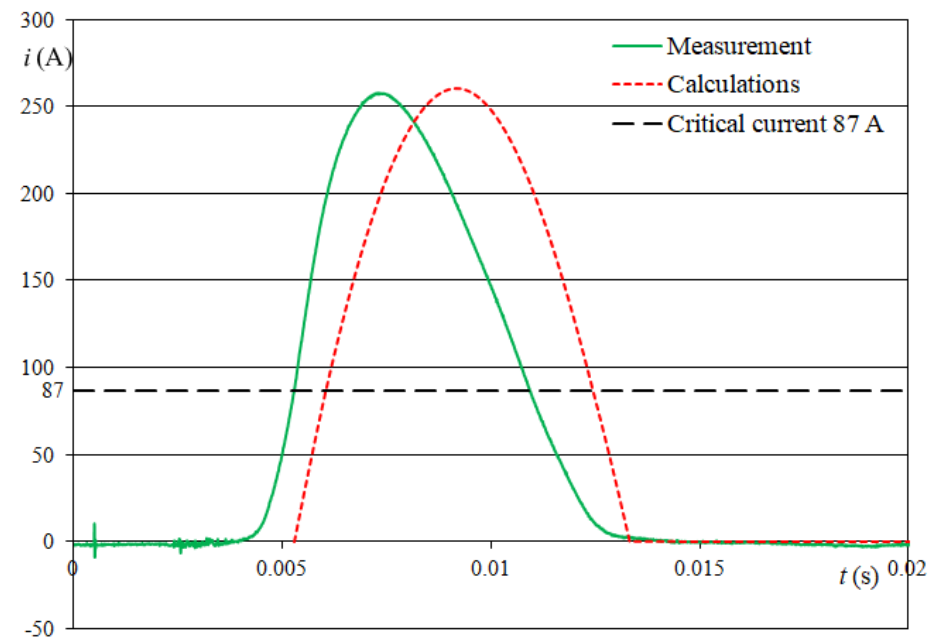

Figure 15. First impulse of inrush current of the $13.8 \mathrm{kVA}$ HTS transformer measured and calculated.

For the $8.5 \mathrm{kVA}$ HTS transformer, the calculated unidirectional current impulse starts approximately 14 degrees earlier and ends approximately 17 degrees after the current pulse obtained from the measurements. The offset between the pulse peaks is approximately 9 degrees. The maximum measured current is $178 \mathrm{~A}$ and the calculated current is $178.2 \mathrm{~A}$.

With the HTS $13.8 \mathrm{kVA}$ transformer, the length of both pulses is similar. However, there is a delay, an impulse calculated relative to the measured one, of approximately 18 degrees at the base and 30 degrees at the top. The maximum measured current is $257.2 \mathrm{~A}$ and the calculated current is $260.7 \mathrm{~A}$.

The time for which the $8.5 \mathrm{kVA}$ transformer winding is in the resistive state is $3.6 \mathrm{~ms}$ for the results obtained from the measurements and $4.4 \mathrm{~ms}$ for the results obtained from 
the calculations. In the case of a $13.8 \mathrm{kVA}$ transformer, the time for which the primary winding is in the resistive state is $5.5 \mathrm{~ms}$ for the results obtained from the measurements and $6.3 \mathrm{~ms}$ for the results obtained from the calculations.

Figures 16 and 17 compare the first five inrush current pulses of both transformers. Table 4 shows a comparison of the measured and calculated maximum values of the first four inrush current pulses of the discussed transformers. Table 5 shows the duration of the first four current pulses for the transformers and Table 6 shows the durations of the interruptions without current between the individual inrush current pulses.

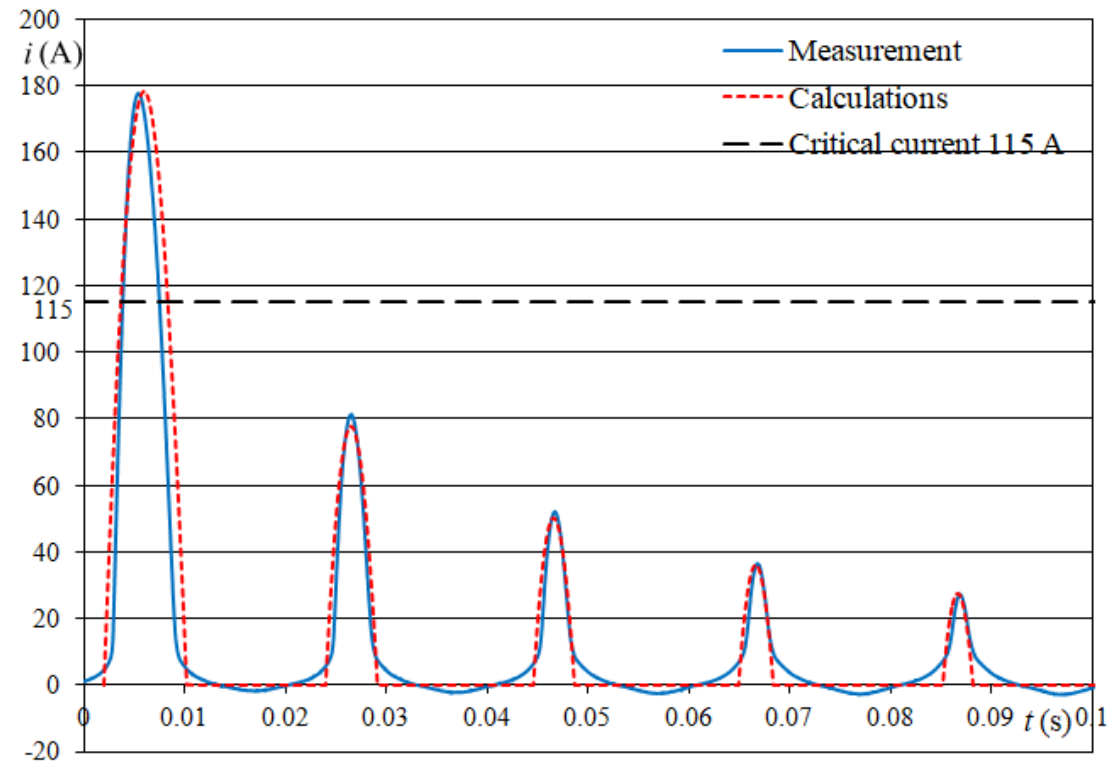

Figure 16. Five consecutive impulses of inrush current of 8.5 kVA HTS transformer, measured and calculated.

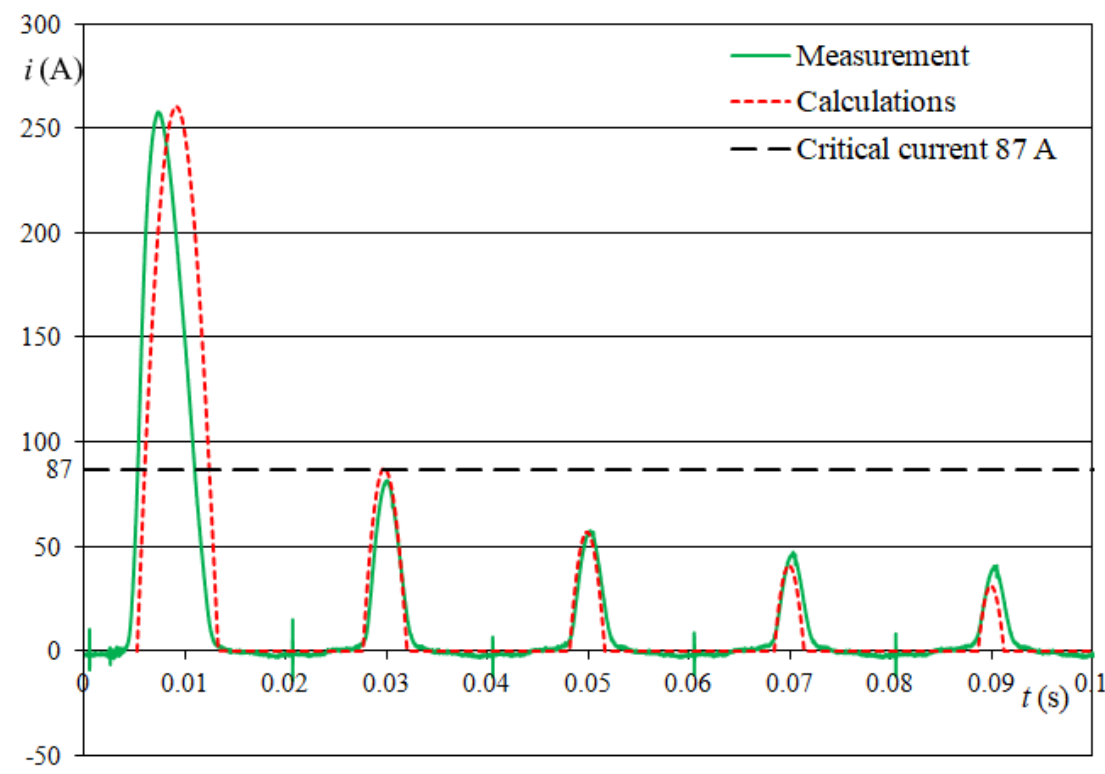

Figure 17. Five consecutive 13.8 kVA HTS transformer inrush current pulses, measured and calculated. 
Table 4. Comparison of the maximum value of the inrush current pulses.

\begin{tabular}{cccccc}
\hline & Pulse no. & $\mathbf{1}$ & $\mathbf{2}$ & $\mathbf{3}$ & $\mathbf{4}$ \\
\hline \multirow{3}{*}{$8.5 \mathrm{kVA}$} & $I(\mathrm{~A})$ (Measurement) & 178 & 81.8 & 51.9 & 36.3 \\
& $I(\mathrm{~A})$ (Calculations) & 178.2 & 79.3 & 50.2 & 36.1 \\
& $\delta, \%$ (Error) & -0.1 & 3.2 & 3.4 & 0.6 \\
\hline \multirow{3}{*}{$13.8 \mathrm{kVA}$} & $I(\mathrm{~A})$ (Measurement) & 257.3 & 80.7 & 56.8 & 45.96 \\
& $I(\mathrm{~A})$ (Calculations) & 260.7 & 87.4 & 57.0 & 41.0 \\
& $\delta, \%$ (Error) & -1.3 & -7.7 & -0.4 & 12.1 \\
\hline
\end{tabular}

Table 5. Comparison of the duration of inrush current pulses.

\begin{tabular}{cccccc}
\hline & Pulse no. & $\mathbf{1}$ & $\mathbf{2}$ & $\mathbf{3}$ & $\mathbf{4}$ \\
\hline \multirow{3}{*}{$8.5 \mathrm{kVA}$} & $\gamma^{\circ}{ }^{\circ}$ (Measurement) & 117.6 & 77 & 62,1 & 56.8 \\
& $\gamma^{\circ}$ (Calculations) & 148 & 92.4 & 73.4 & 62 \\
& $\delta, \%$ (Error) & -20.5 & -16.7 & -15.4 & -8.4 \\
\hline \multirow{3}{*}{$13.8 \mathrm{kVA}$} & $\gamma^{\circ}$ (Measurement) & 156.5 & 88.2 & 80.7 & 76.5 \\
& $\gamma^{\circ}$ (Calculations) & 144.6 & 81.1 & 73.8 & 69.8 \\
& $\delta, \%$ (Error) & 8.2 & 8.8 & 9.3 & 9.6 \\
\hline
\end{tabular}

Table 6. Comparison of the duration of the out-of-current interruptions between current pulses.

\begin{tabular}{cccccc}
\hline & Pulse no. & $\mathbf{1 - 2}$ & $\mathbf{2 - 3}$ & $\mathbf{3 - 4}$ & $\mathbf{4 - 5}$ \\
\hline \multirow{3}{*}{$8.5 \mathrm{kVA}$} & $\varepsilon^{\circ}{ }^{\circ}$ (Measurement) & 272.9 & 291.9 & 297.2 & 313.9 \\
& $\boldsymbol{\varepsilon}^{\circ}$ (Calculations) & 247.6 & 278.2 & 292.8 & 302.4 \\
& $\delta, \%$ (Error) & 10.2 & 4.9 & 1.5 & 3.8 \\
\hline \multirow{3}{*}{$13.8 \mathrm{kVA}$} & $\varepsilon^{\circ}$ (Measurement) & 255.3 & 80.2 & 56.5 & 45.2 \\
& $\varepsilon^{\circ}$ (Calculations) & 260.7 & 78 & 58.9 & 49.2 \\
& $\delta, \%$ (Error) & -2.1 & 2.8 & -4.1 & -8.1 \\
\hline
\end{tabular}

\section{Conclusions}

The proposed method allows the calculation of the inrush current parameters for superconducting transformers with the knowledge of basic electrical quantities (resistance, inductance, voltage) using relatively simple mathematical formulas. These formulas can be easily used in one's own computer programs for calculating the inrush current of both newly designed and existing transformers. Based on the formulas given, not only the maximum value of the inrush current can be estimated, but also the maximum value of all subsequent impulses of this current. It can be estimated by how much the inrush current of the individual pulses exceeds the critical value for the superconductor from which the transformer windings are made. It can also be estimated for how long this individual pulses overshoot will last, and thus how long the superconducting windings will be in a resistive state. The resistive state of superconducting windings should be treated as a state threatening to break the continuity of windings as a result of their thermal damage.

Verification of the results obtained from the calculations with the results obtained from the measurements was carried out only for two superconducting transformers of $8.5 \mathrm{kVA}$ and $13.8 \mathrm{kVA}$. Although good compliance of the inrush current waveforms has been achieved, there is no confirmation of equally good compliance for more transformers, especially for medium and high-power transformers.

Differences in measured and calculated current pulses cannot be overlooked. The simplified shape of the magnetisation curve used in the calculations (Figure 5) translates into differences in the basis of the calculated and actual current pulses. These differences are exacerbated by the omission in the calculations of the steady-state component of the turn-on current, which is in fact the idle current of the transformer. The disadvantage of this method is the lack of consideration of changes in resistance of the transformer winding as a function of temperature changes of the superconductor resulting from the Joule-Lenz phenomenon. 
This is visible in the symmetry of the calculated impulse of the inrush current, which has the same course of ascending and descending slope, differing from the real course, in which the time of current loss is longer than the time of ascending (Figures 14 and 15). The differences between the turn-on current obtained from the measurements and simulations are also caused by the simplified transition characteristics of the superconductor adopted for the calculations.

The present considerations should make us aware of the differences in the inrush current of conventional and superconducting transformers. The calculation of the inrush current of a superconducting transformer from the formulae valid for conventional transformers must lead to large differences between the measured and calculated values.

Funding: This research received no external funding.

Institutional Review Board Statement: Not applicable.

Informed Consent Statement: Not applicable.

Data Availability Statement: Not applicable.

Conflicts of Interest: The authors declare no conflict of interest.

\section{Nomenclature}

A Winding cross-sectional area,

$A_{k} \quad$ Iron cross sectional area of column core,

$B_{m} \quad$ Maximum induction at normal transformer operation,

$B_{r} \quad$ Residual magnetism induction,

$B_{S} \quad$ Saturation induction,

e Circuit supply voltage,

$e_{1} \quad$ Voltage induced in the transformer winding by the main flux,

$E$ Effective value of the circuit supply voltage,

$H_{M}$ magnetic field strength after switching on the transformer,

$i \quad$ Current in the circuit,

$i_{\mu} \quad$ Reactive component of the transformer's no load current,

$I_{\mathrm{Fe}} \quad$ Active component of the transformer's idle current,

$I_{C} \quad$ Critical current of the transformer's primary winding,

$I_{c w}$ Current at which the winding regains its superconductive state,

$L \quad$ Inductance in the circuit when the transformer core is saturated,

$L_{\mu} \quad$ Inductance of the magnetisation branch of the transformer diagram,

$R \quad$ Resistance of the circuit,

$R_{\mathrm{Fe}} \quad$ Resistance of the magnetisation branch of the transformer diagram,

$t$ Time,

$X \quad$ Circuit reactance,

$N \quad$ Number of primary windings of the transformer,

Z Circuit impedance,

$\alpha \quad$ Voltage phase angle,

$\delta \quad$ Angle of phase shift between flow and voltage,

$\varphi \quad$ Magnetic flux,

$\varphi_{f} \quad$ Fixed magnetic flux component,

$\varphi_{d} \quad$ Magnetic flux disturbing component,

$\Phi$ Effective value of the flux,

$\Phi_{m} \quad$ Maximum flux in the core,

$\Phi_{M} \quad$ Peak value of the flux,

$\Phi_{r} \quad$ Residual magnetism flux,

$\Phi_{S}$ Saturation flux of the transformer core,

$\omega \quad$ Pulse 


\section{References}

1. Steurer, M.; Frohlich, K. The Impact of Inrush Current on the mechanical stress on high voltage power transformer coils. IEEE Trans. Power Deliv. 2002, 17, 155-160. [CrossRef]

2. Prikler, L.; Bánfai, G.; Bán, G.; Becker, P. Reducing the magnetizing inrush current by means of controlled energization and de-energization of large power transformers. Electr. Power Syst. Res. 2006, 76, 642-649. [CrossRef]

3. Turner, R.A.; Smith, K.S. Transformer Inrush Current. IEEE Ind. Appl. Mag. 2010, 16, 14-19. [CrossRef]

4. Kasztenny, B. Impact of Transformer Inrush Current on Sensitive Protection Functions. In Proceedings of the IEEE/PES Transmission and Distribution Conference and Exhibition, Dallas, TX, USA, 21-24 May 2006. [CrossRef]

5. Oliveira, A.R.J.C.; Apolonio, R.; Bronzeado, H.S. A Controlled Switching Methodology for Transformer Inrush Current Elimination: Theory and Experimental Validation. In Proceedings of the 11th International Conference on Electrical Power Quality and Utilisation, Lisbon, Portugal, 17-19 October 2011; pp. 1-6. [CrossRef]

6. Chiesa, N.; Hoidalen, H.K. Novel approach for reducing transformer inrush currents: Laboratory measurements, analytical interpretation and simulation studies. IEEE Trans. Power Deliv. 2010, 25, 2609-2616. [CrossRef]

7. Abdulsalam, S.G.; Xu, W. A sequential phase energization method for transformer inrush current reduction-Transient performance and practical considerations. IEEE Trans. Power Deliv. 2007, 22, 208-216. [CrossRef]

8. Taylor, D.I.; Law, J.D.; Johnson, B.K.; Fischer, N. Single-phase transformer inrush current reduction using prefluxing. IEEE Trans. Power Deliv. 2012, 27, 245-253. [CrossRef]

9. Persson, M.; Baig, W.; Thiringer, T. Measurements and modelling of threeand five-limb transformer behaviour during large voltage and frequency disturbances. IET Gener. Transm. Distrib. 2016, 10, 334-340. [CrossRef]

10. Rico, J.J.; Acha, E.; Madrigal, M. The study of inrush current phenomenon using operational matrices. IEEE Trans. Power Deliv. 2001, 16, 231-237. [CrossRef]

11. Adly, A. Computation of inrush current forces on transformer windings. IEEE Trans. Magn. 2001, 37, 2855-2857. [CrossRef]

12. Wu, Q.; Jazebi, S.; Leon, D.F. Parameter estimation of three-phase transformer models for low-frequency transient studies from terminal measurements. IEEE Trans. Magn. 2017, 53, 710-718. [CrossRef]

13. Specht, T.R. Transformer magnetizing inrush current. Trans. Am. Inst. Electr. Eng. 1951, 70, 323-328. [CrossRef]

14. Holcomb, J.E. Distribution transformer magnetizing inrush current. Trans. Am. Inst. Electr. Eng. Part III Power Appar. Syst. 1961, 80, 697-702. [CrossRef]

15. Specht, T.R. Transformer Inrush and Rectifier Transient Currents. IEEE Trans. Power Appar. Syst. 1969, PAS-88, 269-276. [CrossRef]

16. Jamali, M.; Mirzaie, M.; Asghar Gholamian, S. Calculation and Analysis of Transformer Inrush Current Based on Parameters of Transformer and Operating Conditions. Electron. Electr. Eng. 2011, 109, 17-20. [CrossRef]

17. Yacamini, R.; Abu-Nasser, A. Numerical calculation of inrush current in single-phase transformers. IEEE Proc. B Electr. Power Appl. 1981, 128, 327-328. [CrossRef]

18. Vanti, M.G.; Bertoli, S.L.; Cabrai, S.H.L.; Gerent, A.G.; Kuo-Peng, P. Semianalytic solution for a simple model of inrush currents in transformers. IEEE Trans. Magn. 2008, 44, 1270-1273. [CrossRef]

19. Chen, X.; Venkata, S.S. A three-phase three-winding core-type transformer model for low-frequency transient studies. IEEE Power Eng. Rev. 1997, 17, 85-86. [CrossRef]

20. Chen, S.D.; Lin, R.L.; Cheng, C.K. Magnetizing inrush model of transformers based on structure parameters. IEEE Trans. Power Deliv. 2005, 20, 1947-1954. [CrossRef]

21. Chiesa, N.; Hidalen, H.K.; Mork, B.A. Transformer model for inrush current calculations: Simulations, measurements and sensitivity analysis. IEEE Trans. Power Deliv. 2010, 25, 2599-2608. [CrossRef]

22. Faiz, J.; Saffari, S. Inrush current modeling in a single-phase transformer. IEEE Trans. Magn. 2010, 46, 578-581. [CrossRef]

23. Abdulsalam, S.G.; Xu, W.; Neves, W.; Liu, X. Estimation of transformer saturation characteristics from inrush current waveforms. IEEE Trans. Power Deliv. 2006, 21, 170-177. [CrossRef]

24. Naghizadeh, R.A.; Vahidi, B.; Hosseinian, S.H. Modelling of inrush current in transformers using inverse Jiles-Atherton hysteresis model with a neuroshuffled frog-leaping algorithm approach. IET Electr. Power Appl. 2012, 6, 727-728. [CrossRef]

25. Liu, J.; Dinavahi, V. Detailed magnetic equivalent circuit based real-time nonlinear power transformer model on FPGA for electromagnetic transient studies. IEEE Trans. Ind. Electron. 2016, 63, 1191-1202. [CrossRef]

26. Wang, Y.; Abdulsalam, S.G.; Xu, W. Analytical formula to estimate the maximum inrush current. IEEE Trans. Power Deliv. 2008, 23, 1266-1268. [CrossRef]

27. Jazebi, S.; de Leon, F.; Wu, N. Enhanced analytical method for the calculation of the maximum inrush currents of single-phase power transformers. IEEE Trans. Power Deliv. 2015, 30, 2590-2599. [CrossRef]

28. Zirka, S.E.; Moroz, Y.I.; Arturi, C.M.; Chiesa, N.; Hoidalen, H.K. Topology-correct reversible transformer model. IEEE Trans. Power Deliv. 2012, 27, 2037-2045. [CrossRef]

29. Girgis, R.S.; Tenyenuis, E.G. Characteristics of inrush current of present designs of power transformers. IEEE Power Eng. Soc. Gen. Meet. 2007, 12, 1-6. [CrossRef]

30. Bertagnolli, G. Short-Circuit Duty of Power Transformers: The ABB Approach; ABB Trasformatori: Golinelli, Formigine, 1996.

31. Nishimiya, S.; Ishigohka, T.; Ninomiya, A.; Arai, K. Quench Characteristic of Superconducting Transformer by Inrush Current. IEEE Trans. Appl. Supercond. 2007, 17, 1931-1934. [CrossRef] 
32. Meinert, M.; Binder, A. Active damping of inrush and DC-currents for high temperature Superconducting (HTS)-transformers on rail vehicles. IEEE Trans. Appl. Supercond. 2005, 15, 1851-1854. [CrossRef]

33. Abdul Rahman, M.A.; Lie, T.T.; Prasad, K. The Effects of Short-Circuit and Inrush Currents on HTS Transformer Windings. IEEE Trans. Appl. Supercond. 2012, 22, 5500108. [CrossRef]

34. Kalsi, S.S. Applications of High Temperature Superconductors to Electric Power Equipment; Wiley-IEEE Press: Piscataway, NJ, USA, 2011. [CrossRef]

35. Xie, Y.; Marchevsky, M.; Zhang, X.; Lenseth, K.; Chen, Y.; Xiong, X.; Qiao, Y.; Rar, A.; Gogia, B.; Schmidt, R.; et al. Secondgeneration HTS conductor design and engineering for electrical power applications. IEEE Trans. Appl. Supercond. 2009, 19, 3009-3013. [CrossRef]

36. Rupich, M.W.; Li, X.; Sathyamurthy, S.; Thieme, C.L.H.; DeMoranville, K.; Gannon, J.; Fleshler, S. Second Generation Wire Development at AMSC. IEEE Trans. Appl. Supercond. 2013, 23, 6601205. [CrossRef]

37. Nagasawa, T.; Yamaguchi, M.; Fukui, S.; Yamamoto, M. Design requirements of a high temperature superconducting transformer. Phys. C Supercond. 2002, 372-376, 1715-1718. [CrossRef]

38. Berger, A.; Cherevatskiy, S.; Noe, M.; Leibfried, T. Comparison of the efficiency of superconducting and conventional transformers. J. Phys. Conf. Ser. 2010, 234, 032004. [CrossRef]

39. Chang, H.; Choi, Y.S.; Sciver, S.W.; Baldwin, T.L. Cryogenic cooling temperature of HTS transformers for compactness and efficiency. IEEE Trans. Appl. Supercond. 2003, 13, 2298-2301. [CrossRef]

40. Wilson, M.N. Superconducting Magnets; Oxford University Press: New York, NY, USA, 1990.

41. Lei, H.; Wang, K.; Hu, R.; Ryu, H.; Abeykoon, M.; Bozin, E.S.; Petrovic, C. Iron chalcogenide superconductors at high magnetic fields. Sci. Technol. Adv. Mater. 2012, 13, 054305. [CrossRef]

42. Yahiou, A.; Bayadi, A. Transformer core modeling for magnetizing inrush current investigation. Semantic Scholar. Mater. Sci. 2015, 1, 077-088.

43. Yonezawa, R.; Noda, T.; Suzuki, N.; Nagashima, H.; Nomiyama, F.; Yamaguchi, N.; Honma, H.; Kitamura, S. Development of a transformer magnetizing circuit model for inrush current and residual flux calculations. IEEE Trans. Power Energy 2014, 134, 749-758. [CrossRef]

44. Vahidi, B.; Bank Tavakoli, M.R.; Gharehpetian, G.B.; Hosseinian, S.H. An Algorithm for Evaluating Inrush Current in Transformers Using Jiles-Atherton Theory of Ferromagnetic Hysteresis. In Proceedings of the TENCON 2006-2006 IEEE Region 10 Conference, Hong Kong, China, 14-17 November 2006. [CrossRef]

45. Sima, W.; Liu, Y.; Sun, P.; Zhou, Y.; Peng, D.; Yang, M. The Effect of Different Core Materials on Transformer Inrush Currents. In Proceedings of the IEEE International Magnetic Conference (INTERMAG), Singapore, 23-27 April 2018. [CrossRef]

46. Taillefer, P.; Poutrain, L.; Sanchez, J. Limiting Voltage Dips \& Inrush Currents When Energizing Power Transformers Controlled Switching of Gang Operated Switches-Theory and Case Study. In Proceedings of the 2018 IEEE/PES Transmission and Distribution Conference and Exposition (T \& D), Denver, CO, USA, 16-19 April 2018. [CrossRef]

47. Huang, Z.; Jia, Z.; Li, Z. Research on Transformer Saturation Characteristics of Electric Locomotive Based on Flux-Current Loop Model. In Proceedings of the 2019 9th International Conference on Power and Energy Systems (ICPES), Perth, Australia, 10-12 December 2019. [CrossRef]

48. Sonnemann, W.K.; Wagner, C.L.; Rockefeller, G.D. Magnetizing Inrush Phenomena in Transformer Banks. Trans. Am. Inst. Electr. Eng. Part III Power Appar. Syst. 1958, 77, 884-892. [CrossRef]

49. Wojtasiewicz, G.; Janowski, T.; Kozak, S.; Kozak, J.; Majka, M.; Kondratowicz-Kucewicz, B. Tests and Performance Analysis of 2G HTS Transformer. IEEE Trans. Appl. Supercond. 2013, 23, 5500505. [CrossRef]

50. Komarzyniec, G. 14 kVA superconducting transformer with (RE)BCO windings. In Proceedings of the 2017 International Conference on Electromagnetic Devices and Processes in Environment Protection with Seminar Applications of Superconductors (ELMECO \& AoS), Nałęczów, Poland, 3-6 December 2017. [CrossRef]

51. Wojtasiewicz, G.; Komarzyniec, G.; Janowski, T.; Kozak, S.; Kozak, J.; Majka, M.; Kondratowicz-Kucewicz, B. Inrush Current of Superconducting Transformer. IEEE Trans. Appl. Supercond. 2013, 23, 5500304. [CrossRef] 